\title{
formação de classe e participação política: E. P. Thompson e o populismo
}

Alexandre Fortes*

Resumo: $\mathrm{O}$ artigo enfoca o uso do conceito de populismo e a análise de fenômenos correlatos nos trabalhos do historiador britânico E. P. Thompson, particularmente $A$ formação da classe operária inglesa. A relevância desse exercício, do ponto de vista da história do trabalho no Brasil, repousa na influência recentemente adquirida pelos trabalhos de Thompson como referencial teórico para a análise da participação política da classe trabalhadora no pós-1930, tema tradicionalmente abordado precisamente à luz daquele conceito.

Palavras-chave: Populismo. História social britânica. E. P. Thompson. Classe trabalhadora. Participação política.

\section{Introdução}

O presente artigo enfoca o uso do conceito de populismo e a análise de fenômenos correlatos nos trabalhos do historiador britânico E. P. Thompson, particularmente A formação da classe operária inglesa (THOMPSON, 1987a). A relevância desse exercício, do

* Professor do Programa de Pós-Graduação em História da Universidade Federal Rural do Rio de Janeiro (UFRRJ). E-mail: alexfortes@globo.com. 
ponto de vista da história do trabalho no Brasil, repousa na influência recentemente adquirida pelos trabalhos de Thompson como referencial teórico para a análise da participação política da classe trabalhadora no pós-1930, tema tradicionalmente abordado à luz daquele conceito.

Num primeiro momento, analisamos os argumentos encontrados em alguns trabalhos da produção historiográfica brasileira recente segundo os quais o uso do conceito de "populismo" seria incompatível com as ideias de Thompson. A seguir, examinamos o modo como o termo "populismo" (ou o adjetivo "populista") aparece em A formação da classe operária inglesa, bem como trechos desse clássico da história social em que fenômenos similares ao "populismo" são analisados pelo autor. Por fim, sistematizamos algumas ideias sobre a contribuição das questões aqui analisadas para a continuidade das pesquisas e do debate historiográfico brasileiro sobre a participação política da classe trabalhadora.

\section{Thompson e o debate sobre o populismo no Brasil}

A obra do historiador britânico E. P. Thompson tem exercido forte influência na renovação da produção historiográfica brasileira. Um dos campos em que essa influência tem sido crescente é o dos estudos sobre a relação entre a classe trabalhadora urbana e o "populismo", tema que Chalhoub e Silva (2009, p. 30, 34-39), num balanço recente, apontaram com uma das três principais "vertentes de investigação" que, a partir do final dos anos 1970, ampliaram o horizonte dos estudos sobre a presença dos trabalhadores na história brasileira do século XX.

Ângela de Castro Gomes (1988, p. 16-19), em $A$ invenção do trabalbismo - trabalho que se estabeleceu como um dos marcos fundamentais do novo momento no debate historiográfico sobre o tema -, já apontava Thompson como um dos autores que teria inspirado abordagens pautadas pela valorização da lógica simbólica nos estudos sobre a classe trabalhadora. Fazendo um balanço posterior da evolução da produção acadêmica sobre o tema, Gomes situa na passagem da década de 1970 para a de 1980 a renovação 
das abordagens no próprio campo marxista, indicada a seu ver pela tendência à substituição de Gramsci por Thompson como referência teórica. Essa nova inspiração teria expressado um abalo nas "orientações teleológicas que postulavam um certo modelo de consciência de classe revolucionária para o operariado", a partir das quais se formulavam interpretações que rotulavam como "desvio" ou "inconsciência" todas as formas de ação dos trabalhadores que "não preenchendo os requisitos delineados, interferiam no curso dos acontecimentos históricos que insistiam em não seguir o curso imaginado" (GOMES, 2001, p. 43-44).

Nas abordagens criticadas por Gomes, o conceito de "populismo" era tradicionalmente utilizado em referência precisamente a esse tipo de "desvio". É, portanto, compreensível que, em reação a essas concepções anteriormente dominantes, a forma predominante pela qual o trabalho de Thompson veio a ser invocado pela historiografia mais recente nesse campo de estudos seja a alegação de que a abordagem thompsoniana, caracterizada pela ênfase na "agência" dos trabalhadores - ou seja, sua capacidade de intervenção ativa no processo histórico -, seria contraditória com o próprio uso do conceito de "populismo", o qual, segundo esse ponto de vista, implica inevitavelmente a negação dessa mesma capacidade aos trabalhadores. Esse ponto de vista é explicitado por Jorge Ferreira (2001, p. 101, grifo do autor), para quem "a concepção que o historiador inglês tem de classe social e de consciência de classe é incompativel com a noção de populismo", pois este último estaria inevitavelmente associado a "manipulação de massas, mistificação ideológica e consciências desviadas de seus interesses 'reais"'.

Entretanto, um uso diverso da obra de Thompson nas reflexões sobre a relação entre trabalhadores e "populismo" pode ser percebido em outros autores, tais como Fernando Teixeira da Silva e Hélio da Costa. Os dois autores identificam nas análises do historiador britânico sobre o conceito de "paternalismo" uma chave para repensar o significado do "populismo", sem, entretanto, descartar o uso do termo. Silva e Costa (2001, p. 224) reconhecem as flagrantes "diferenças entre as peculiaridades da sociedade inglesa dos setecentos e as condições históricas do populismo brasileiro". 
Acreditam, porém, que a noção de hegemonia utilizada por Thompson pode ser aplicada em contextos distintos do original como instrumento "para perceber como os trabalhadores retiraram da ideologia formal do 'modelo paternalista' os recursos necessários às suas demandas e lutas", realizando uma apropriação seletiva das "noções de justiça social e ressignificando-as conforme suas experiências e expectativas" (SILVA; COSTA, 2001, p. 224).

Conforme demonstraremos mais adiante, afirmações tão categóricas quanto as de Ferreira (2001) sobre a incompatibilidade entre as ideias thompsonianas e o conceito de populismo podem ser questionadas, em primeiro lugar, com base na própria utilização eventual do termo (ou do adjetivo "populista") por Thompson como instrumento de análise em suas obras. Não é, entretanto, essa motivação exegética que nos move aqui. Ou seja, não se trata de avaliar se uma "adesão" ou "afiliação" thompsoniana "autoriza" ou "desautoriza" o uso de um determinado conceito. O que buscamos é, a partir da análise do modo como o termo "populismo" ou questões tradicionalmente associadas ao debate sobre o tema aparecem em A formação da classe operária inglesa (THOMPSON, 1987a), oferecer uma contribuição para a reflexão sobre algumas questões teóricometodológicas fundamentais para o estudo das relações entre classe trabalhadora e processo político.

Conforme temos argumentado em outros trabalhos (FORTES, 2006; FORTES; SILVA, 2007), com grande frequência o desdobramento prático da "inspiração thompsoniana" no Brasil tem se restringido à citação de algumas formulações nas quais Thompson buscou sintetizar suas ideias sobre o processo de formação de classe como, por exemplo, a introdução de $A$ formação e trechos de A miséria da teoria (THOMPSON, 1981). Esse tipo de apropriação traz o risco da descontextualização das ideias do autor, que muitas vezes são usadas como "palavras de ordem" invocadas no combate contra adversários teóricos imprecisos ou caricaturados. Temos sugerido que, ao contrário, a contribuição proporcionada pela leitura dos trabalhos de Thompson à renovação da pesquisa histórica torna-se mais rica à medida que uma maior atenção é dedicada ao modo como o autor opera na análise de processos históricos concretos ao longo de suas obras. Essa abordagem, 
acreditamos, é inclusive mais coerente com o primado da realidade empírica na produção do conhecimento histórico defendida pelo próprio autor (THOMPSON, 1981).

No que diz respeito ao tema deste artigo, concordamos com as considerações de Gomes (2001), citadas acima, de que a crítica à visão teleológica presente nas concepções deterministas do marxismo é uma das características marcantes da nova história social brasileira, e que Thompson tem sido uma importante fonte de inspiração na busca de abordagens que incorporem a "agência" dos trabalhadores em lugar de destaque nas análises. Entretanto, o risco decorrente da descontextualização das ideias do historiador britânico, conforme comentamos no parágrafo anterior, é que a teleologia venha a ser substituída por uma visão essencialista. $\mathrm{Ou}$ seja, da recusa aos julgamentos sobre a ação histórica da classe trabalhadora deduzidos de uma concepção predeterminada do que essa classe "deveria ser", podemos cair numa postura radicalmente oposta, que se limita a "regatar" e "celebrar" a classe como ela supostamente "é". No exame do Brasil pós-1945, uma expressão dessa abordagem essencialista pode ser percebida na identificação do "trabalhismo" como expressão unívoca da consciência de classe dos trabalhadores. ${ }^{1}$ Nesse caso, tanto quanto no de uma abordagem teleológica, reduz-se significativamente a capacidade de problematização do "vir a ser", aberto a conflitos e a resultados em grande medida indeterminados, que caracteriza o processo histórico.

O olhar que lançaremos ao trabalho de Thompson nas próximas seções deste artigo busca elementos para enriquecer a reflexão sobre essas questões. Para isso, adotaremos uma abordagem distinta da que tem sido encontrada em outros trabalhos que têm buscado compatibilizar o uso das ideias de Thompson com o conceito de "populismo" (ou melhor, "sistema político populista"), como os anteriormente mencionados (SILVA; COSTA, 2001; ver também NEGRO, 2004, p. 16-21). Referimo-nos ao fato de que, nos trabalhos mencionados, as obras do historiador britânico analisadas têm sido em geral aquelas dedicadas ao estudo do "paternalismo" na Inglaterra do século XVIII, particularmente os reunidos nas coletâneas Costumes em comum (THOMPSON, 2002) e Tradición, revuelta y 
consciencia de clase (THOMPSON, 1989), assim como o livro Senhores e caçadores (THOMPSON, 1987b).

Aqui, por outro lado, optamos por analisar o modo como o tema perpassa A formação da classe operária inglesa (THOMPSON, 1987a). Nesse trabalho clássico, Thompson analisa a conjuntura que se inicia com a difusão da ideia de auto-organização popular visando à participação política ("um número ilimitado de membros"), sob o impacto da Revolução Francesa, e se encerra com amadurecimento de cultura operária ("consciência de classe") e diferenciação em relação às "classes médias", que se evidencia na reforma eleitoral de 1832, cuidadosamente elaborada para estabelecer uma linha divisória entre esses dois segmentos sociais. Como buscaremos demonstrar abaixo, acompanhar o autor em alguns trechos desse percurso pode nos trazer elementos interessantes para a reflexão sobre algumas das questões centrais do debate sobre trabalhadores e populismo no Brasil do século XX.

\section{Usos do termo "populismo" em $A$ formação da classe operária inglesa}

Os termos "populismo" ou "populista", aparecem em três ocasiões em A formação da classe operária inglesa. Apontaremos abaixo o contexto dessas menções, para, a seguir, analisar os sentidos do uso do conceito por Thompson.

A primeira dessas ocasiões é a análise do autor sobre a "Westminster Radical", ou seja, sobre a particularidade da mobilização e participação política radical no distrito de Londres que sedia o próprio parlamento. Ali, uma combinação entre uma composição social peculiar, marcada pela alta concentração de artesãos e pequenos comerciantes, e experiências com técnicas inovadoras de organização político-eleitoral possibilitaram a eleição de um membro "radical" para a Câmara dos Comuns, em 1807. Thompson aponta o surgimento de uma nova noção de "independência" política como o ganho mais significativo decorrente dessa vitória eleitoral. Até então, o termo era associado à ideia de que era fundamental que os candidatos, fossem eles Whigs ou Tories, 
possuíssem riquezas e terras, o que, supostamente, "torná-los-ia 'independentes' da necessidade de bajular Ministros ou Rei para conseguir favores ou cargos". Mas, na campanha de 1807, os propagandistas radicais, com destaque para William Cobbett, atribuíram-lhe um novo sentido, ao enfatizar que a "independência" era um "dever dos eleitores, fossem proprietários alodiais, comerciantes ou artesãos", que deveriam "se libertar com seus próprios esforços do patronato, do suborno e da submissão". Mais do que isso, o Comitê de Westminster, que era integrado basicamente por artesãos, assalariados e pequenos comerciantes (о menu peuple londrino, como o classifica Thompson remetendo à composição dos clubes jacobinos durante a Revolução Francesa), organizou a campanha vitoriosa "independentemente dos seus próprios candidatos", o que fortaleceu o sentimento de que ela representava uma conquista popular. Ela teria "oferecido um exemplo impressionante de eficácia de um novo tipo de organização eleitoral", na qual o fator decisivo não mais seria a "riqueza ou influência do candidato", mas sim "os empenhos voluntários dos eleitores". (THOMPSON, 1987 a, v. 3, p. 27-28).

O uso do adjetivo "populista" surge na análise dos desdobramentos dessa vitória eleitoral dos radicais. Para Thompson (1987a, v. 3, p. 27-28, grifo nosso), em função dos fatores mencionados acima, "o povo de Westminster sentiu a vitória como sua", mas:

Seria errôneo, porém, sugerir que o Comitê de Westminster conduziu um movimento independente "populista", e menos ainda operário. $\mathrm{O}$ eleitorado (compreendendo cerca de 18.000 chefes de família em 1818) incluía muitos artífices independentes e alguns artesãos. Mas o tom, cada vez mais, era dado pelos pequenos mestres e comerciantes.

"Populista" surge aqui, claramente, como uma classificação intermediária entre o radicalismo que mobiliza os trabalhadores manuais ainda sob direção da pequena burguesia ("pequenos mestres e comerciantes") e um movimento "operário" com condução autônoma. $\mathrm{Na}$ avaliação de Thompson, apesar do valor positivo 
da valorização de uma nova noção de "independência", comentada acima, o Comitê de Westminster, portanto, não teria sido sequer "populista", pois no seu interior estaria acontecendo um retrocesso no que diz respeito à própria aposta no protagonismo popular. $\mathrm{O}$ comitê vinha mostrando "sérias limitações enquanto organização democrática”, e seu principal organizador, Francis Place, vinha encampando cada vez mais a filosofia do liberalismo utilitarista das "classes médias respeitáveis" e "tinha se tornado amigo íntimo de Bentham e James Mill". Place tornava-se cada vez mais hostil à atuação de tribunos e jornalistas radicais, como James Hunt e William Cobbett, e aos "métodos de agitação entre 'um número ilimitado de membros" que caracterizavam as organizações jacobinas britânicas desde a criação da Sociedade Londrina de Correspondência, examinada por Thompson no primeiro capítulo do seu livro. Na visão de Place, portanto, o Comitê de Westminster reduzia-se ao papel de "um local útil de onde podiam se mexer os pauzinhos em favor dos interesses do artesão sóbrio e estudioso" e, desse modo, afastava-se do conjunto mais amplo e heterogêneo dos trabalhadores de Londres (THOMPSON, 1987a, v. 3, p. 2829).

A segunda menção ao "populismo" pode ser encontrada no capítulo "Demagogos e mártires" (THOMPSON, 1987a, v. 3, p. 181-302). Ao analisar o levante de Pentridge, tentativa insurrecional articulada clandestinamente nos distritos industriais das áreas centrais e nortistas da Inglaterra, Thompson rejeita a ideia, consagrada até então na historiografia do movimento operário britânico, que atribui não apenas a derrota do movimento, mas sua própria existência, à ação de um agente provocador infiltrado, a soldo do Ministério do Interior, que se tornou conhecido como "Oliver, o espião". Um amplo trabalho de análise da bibliografia e de diversas fontes primárias leva Thompson a concluir que, apesar do movimento estar condenado de antemão à derrota tanto pela espionagem quanto pelas suas fragilidades intrínsecas, ele expressava sentimentos e processos de organização altamente representativos da realidade dos trabalhadores daquela parte do país. Nesse sentido, poderia ser visto como "uma das primeiras tentativas da 
história de se empreender uma insurreição totalmente proletária, sem nenhum apoio da classe média":

A tentativa lança luz sobre o extremo isolamento a que, durante as Guerras, tinham sido obrigados os trabalhadores do norte e das Midlands, e é um movimento de transição entre o luddismo e o radicalismo "populista" de 1818-20 e 1830-32. (THOMPSON, 1987a, v. 3, p. 255, grifo nosso).

Essa passagem é altamente reveladora, e articula duas ideias distintas, que merecem ser examinadas mais detalhadamente. A primeira delas é que a tentativa insurrecional analisada é situada como um ponto de inflexão num processo que liga, de um lado, os movimentos clandestinos de ação direta anteriores baseados em comunidades ocupacionais específicas, concentradas em algumas regiões que sofriam os fortes impactos desestruturantes gerados pelas transformações tecnológicas, econômicas e jurídicas decorrentes da "revolução industrial" (o luddismo) e, de outro lado, as mobilizações de massas em escala nacional entre amplos e heterogêneos contingentes de trabalhadores cujo "ensaio" ocorreu em 1818-1820 e que vieram a atingir sua máxima amplitude em 18301832. A segunda é a classificação desses movimentos de massas como "radicalismo populista", o que traz elementos interessantes para a reflexão sobre a relação entre "populismo" e "classe" na obra de Thompson.

A terceira e última menção ao "populismo" em $A$ formação encontrada no último capítulo do livro, "Consciência de classe" (THOMPSON, 1987a, v. 3, p. 303-440) -, confirma o entendimento indicado acima sobre o sentido atribuído por Thompson ao termo. Ao analisar as transformações perceptíveis na "nova consciência de classe dos trabalhadores" que a seu ver poderia ser identificada na conjuntura 1830-1834, o autor identifica dois aspectos centrais. Em primeiro lugar, "uma consciência da identidade de interesses entre os trabalhadores das mais diversas profissões e níveis de realização" que estaria "encarnada em muitas formas institucionais e expressa, numa escala sem precedentes, no sindicalismo geral". Para efeitos de contraste com o momento tomado 
como ponto de partida na periodização do livro, Thompson aponta que "essa consciência e essas instituições só se encontrariam em forma fragmentária na Inglaterra de 1780”.

O segundo aspecto diz respeito à relação entre consciência de classe e projetos políticos. Para Thompson, a "consciência da identidade dos interesses da classe operária, ou "classes produtivas', enquanto contrário ao de outras classes" vinha levando ao amadurecimento da "reivindicação de um sistema alternativo". Essa transformação no âmbito da consciência política, entretanto, não resultava de uma determinação automática das mudanças na estrutura social, ao contrário, "a definição final dessa consciência de classe era conseqüência, em grande parte, da reação da classe média à força operária", que se consubstanciou no estabelecimento de uma clara linha divisória na definição das habilitações de voto estabelecidas pela reforma eleitoral de 1832. Para Thompson, a "característica singular do desenvolvimento inglês" em relação aos processos semelhantes ocorridos ao longo do século XIX em outros países europeus é que, ao invés de "um crescente movimento de classe média pela reforma, com uma rabeira operária", ocorreu o contrário. Para o autor, essa peculiaridade pode ser explicada pela combinação entre três processos simultâneos desencadeados em solo britânico pelo exemplo da Revolução Francesa:

Uma reação contra-revolucionária despertada por pânico, da parte da aristocracia fundiária e comercial; um recuo por parte da burguesia industrial e uma acomodação (em termos favoráveis) ao status quo; e uma rápida radicalização do movimento popular pela reforma, a ponto de os quadros jacobinos suficientemente rijos para sobreviver às Guerras serem, em sua maioria, pequenos mestres, artesãos, malharistas e cortadores de tecido, e ou outros trabalhadores.

Os vinte e cinco anos após 1795 podem ser vistos como os anos da longa contra-revolução; por conseguinte, o movimento radical manteve um caráter largamente operário, tendo como teoria um populismo democrático avançado. Mas a vitória de um tal movimento 
dificilmente seria bem-recebida pelos donos de fábricas, donos de fundições e manufatureiros. (THOMPSON, 1987a, v. 3, p. 411-412, grifo nosso).

É fundamental examinar aqui o conjunto de termos adotados por Thompson ao examinar o processo descrito no livro e o seu resultado final. De um lado, um "movimento radical", porém, devido a peculiaridades históricas inglesas, com um "caráter largamente operário". De outro, um "populismo" que o autor faz questão de qualificar como "democrático e avançado". O raciocínio torna-se ainda mais interessante se unirmos a análise das passagens acima com outra, na qual o autor busca precisar o que significa dizer que a classe operária inglesa havia concluído o seu "fazer-se" ao final deste processo:

De 1830 em diante, veio a amadurecer uma consciência de classe, no sentido marxista tradicional, mais claramente definida, com a qual os trabalhadores estavam cientes de prosseguir por conta própria em lutas antigas e novas. (THOMPSON, 1987 a, v. 3, p. 304, grifo nosso).

Numa síntese preliminar, poderíamos dizer, portanto, que Thompson (1987a, v. 3, p. 304, 411-412) considera que um movimento radical de caráter largamente operário, tendo como teoria um "populismo democrático avançado", foi o meio pelo qual a classe trabalhadora inglesa chegou a forjar uma "consciência de classe, no sentido marxista tradicional". É evidente que essas considerações levam necessariamente a um reexame das supostas conexões automáticas entre "populismo" e "desvio da consciência de classe" ou "manipulação política".

\section{Demagogos, mártires e a participação política dos trabalhadores}

Mas não é apenas nas menções explícitas ao termo "populismo" que os problemas históricos tradicionalmente analisados com base nesse conceito podem ser localizados em $A$ formação. Ao longo do livro, encontramos diversas referências a certas relações 
entre trabalhadores e lideranças políticas nas quais podemos identificar questões similares àquelas presentes no debate sobre "populismo" no Brasil.

O primeiro exemplo digno de menção é o de John Wilkes, jornalista e deputado radical que introduziu, em 1776, o primeiro projeto de reforma eleitoral no Parlamento Britânico. Famoso por seus ataques ao establishment político, Wilkes sofreu perseguições, cassações de mandatos e chegou a ser aprisionado por "libelo sedicioso", o que só aumentava a sua popularidade entre a multidão londrina, que em diversas ocasiões se mobilizou em sua defesa aos gritos de "Wilkes e Liberdade". Como destaca Thompson (1987a, v. 1, p. 73), tratava-se de uma "turba em transição, em vias de se tornar uma multidão radical autoconsciente". A liderança de Wilkes ajudava a catalisar os resultados dos processos de transformação na cultura política gerados pelo "fermento da Dissidência e da educação política". Essa confluência dava "ao povo uma predisposição para assumir a defesa das liberdades populares, desafiando as autoridades" (THOMPSON, 1987a, v. 1, p. 73).

Sem negar a importância da "agitação wilkista" na transformação da consciência política dos setores populares londrinos, Thompson mantém, entretanto, um claro distanciamento crítico ao classificar esse movimento, o que pode ser percebido na sua análise sobre o trabalho do primeiro historiador marxista britânico a estudá-lo, Georges Rudé (1962). Ambos convergem na identificação do "wilkismo" como um "movimento de protesto social", no qual se pode perceber o "conflito subjacente dos pobres contra os ricos". Thompson valoriza o papel do estudo de Rudé por ele "resgatar a multidão londrina da acusação de ser composta apenas por simples arruaceiros e "elementos criminosos", demonstrando a diferença entre a "a ebulição espontânea da maioria wilkista" e "os valentões pagos para apoiar o candidato antiwilkista, Proctor". A seu juízo entretanto, Rudé, “ao protestar contra o 'preconceito' dos historiadores", exagerou na dose:

Pois a multidão wilkista dos anos 1760 e 1770 mal começara a desenvolver sua própria organização ou liderança; tinha poucas idéias próprias diferentes das de seus "dirigentes"; 
e, num certo sentido ela era manipulada e estimulada por Wilkes para "agir a favor de interesses externos" - os interesses dos ricos comerciantes, mercadores e manufatureiros de Londres, que eram os partidários mais influentes de Wilkes. (THOMPSON, 1987a, v. 1, p. 74).

Essa instrumentalização da mobilização popular por parte de setores das classes dominantes, segundo Thompson, poderia ser percebida claramente durante os "distúrbios de Gordon", em 1780 , causados pela recusa do parlamento em discutir uma petição popular apresentada pacificamente. Naquela ocasião, enquanto casas de católicos ricos e suas igrejas, assim como o Banco da Inglaterra, eram atacadas, a "turba" não enfrentava qualquer repressão por parte das "autoridades wilkistas" a cargo do governo municipal de Londres, o que lhe conferia "o sentido de uma multidão 'autorizada"'. Essa atitude complacente se explicaria, segundo o autor, por dois motivos. De um lado, o "medo de incorrer no ódio popular", de outro, "uma conivência efetiva com as desordens que os fortaleciam contra o Rei e seu governo." (THOMPSON, 1987a, v. 1, p. 76). A superação dessa possibilidade de manipulação das massas, viria, de acordo com Thompson, nas décadas seguintes, com a difusão das "ideias jacobinas" e o fortalecimento da cultura autodidata cuja expressão máxima era o estudo e debate, por parte dos artesãos, de livros como Os direitos do homem, de Tom Paine. A partir daí, "os homens não mais se dispunham a esperar o exemplo de um Wilkes ou de um Wyvill para iniciarem uma agitação democrática" (THOMPSON, 1987a, v. 1, p. 202).

Mas o surgimento do jacobinismo - e com ele do modelo de organização política autônoma herdado pelo movimento operário - não eliminou de imediato o papel de líderes políticos, geral-mente originários de extratos sociais superiores, nas lutas populares. No capítulo intitulado "Demagogos e mártires" (THOMPSON, 1987a, v. 3, p. 181-302), Thompson analisa a dependência do movimento radical das primeiras décadas do século XIX em relação a oradores ("tribunos populares") e jornalistas que cumpriam o papel de elos de articulação nacional entre os movimentos locais de trabalhadores, 
diante da sua fragilidade organizacional e do isolamento imposto pelo contexto de repressão política. Seus comentários sobre um desses líderes, Henry Hunt, são emblemáticos. Para Thompson, Hunt "possuía tanto as qualidades como os defeitos dos demagogos", encontrados em "uma série de líderes do período", e, portanto, típicos "do movimento da época". Como todo demagogo, Hunt teria sido "um líder ruim ou ineficaz", que "expressava não o princípio e nem sequer uma estratégia radical bem formulada, mas as emoções do movimento" e na verdade se constituía em um "prisioneiro da parcela mais instável da multidão" (THOMPSON, 1987a, v. 3, p. 211-212). O peso adquirido por esse tipo de orador expressava "a velha tradição wilkista, que se rompia apenas lentamente, pela qual mesmo o movimento democrático buscava um líder aristocrático ou fidalgo", pois essa origem social era ainda tinha como precondição para o domínio das "formas e a linguagem da grande política, somente ele podia fazer boa figura nos palanques eleitorais ou invectivar os ministros em sua própria língua”. Portanto, apesar do movimento pela reforma "empregar a retórica da igualdade", o autor considera que "muitas das velhas reações de submissão ainda persistiam, mesmo entre as multidões aclamantes" (THOMPSON, 1987 a, v. 3, p. 203).

Buscando compreender o tom demagógico que caracterizava esses líderes, Thompson define-o como "inevitável num movimento popular excluído do poder ou da esperança de poder que estimulava a retórica totalmente improdutiva da denúncia". Nessas lutas, "mártires e intrépidos organizadores voluntários" ombreavam com "bêbados, tesoureiros fugidos e efêmeros jornalistas briguentos" e ambos os grupos comungavam de uma linguagem "bombástica e flamejante". O estilo oratório do movimento popular, portanto, "era-lhe dado pelas frustrações dos indivíduos a que se dirigia". Os fatores determinantes para a "exaltação dos demagogos", entretanto, são buscados por Thompson nas debilidades do movimento radical:

Em nível nacional, o radicalismo nunca conheceu a autodisciplina de uma organização política. Como qualquer partido ou centro de correspondência era ilegal, e como nenhum executivo eleito determinava a política e a estratégia, 
a liderança caiu inevitavelmente nas mãos de oradores e jornalistas individuais. Divergências reais sobre questões políticas convertiam-se em invejas pessoais; da mesma forma, o líder cuja política era aprovada por aclamação popular, aí encontrava alimento para sua vaidade pessoal. As condições da agitação geraram a personalização das questões. A grande reunião de massa exigia uma figura de proa exuberante. (THOMPSON, 1987a, v. 3, p. 204).

Diversos outros exemplos de análises críticas de Thompson sobre o papel de líderes oriundos das classes dominantes nos movimentos "radicais", "populares" ou "de trabalhadores" poderiam ser citados e analisados. Selecionamos, entretanto, Robert Owen como o último caso a ser abordado, pela relevância atribuída pelo próprio Thompson ao "owenismo" no processo de formação da classe trabalhadora inglesa. Como destaca o autor, "a estória de Robert Owen de New Lanark é muito conhecida, e até lendária":

O dono de fábrica paternalista e self-made man exemplar que apresentava solicitações à realeza, cortesãos e governos da Europa para suas propostas filantrópicas; a exasperação crescente do tom de Owen à medida que se deparava com aplausos corteses e desestímulos práticos; sua propaganda para todas as classes e sua proclamação da vinda do Milênio; o interesse crescente pelas suas idéias e promessas entre alguns setores de trabalhadores; a ascensão e queda das primeiras comunidades experimentais, em especial Orbiston; a partida de Owen para os Estados Unidos, para outros experimentos em formação de comunidades (1824-29); a crescente adesão ao owenismo durante sua ausência, o enriquecimento de sua teoria por Thompson, Gray e outros, e a adoção de uma espécie de owenismo por alguns sindicalistas; a iniciativa do Dr. King em Brighton, com seu Cooperator (1828-30) e os experimentos amplamente disseminados de comércio cooperativo; a iniciativa de alguns artesãos londrinos, entre os quais se destacava Lovett, em promover uma propaganda nacional segundo princípios 
cooperativos (a Associação Britânica para a Promoção do Conhecimento Cooperativo) em 1829-30; a maré ascendente depois da volta de Owen, quando se viu, quase a contragosto, na liderança de um movimento que levou ao Grande Sindicato Nacional Consolidado. (THOMPSON, 1987 a, v. 3, p. 380-381).

Essa retrospectiva factual torna-se necessária para compreender os argumentos de Thompson, segundo os quais "o socialismo posterior de Owen sempre guardou as marcas de sua origem", fazendo com que ele se portasse como "bondoso Papai do Socialismo". Apesar de genuinamente "admirável e generoso", Owen teria sido, num certo sentido, "o ne plus ultra do utilitarismo, planejando a sociedade como um gigantesco panopticon industrial", completamente estranho à "idéia de avanço operário em direção a seus próprios objetivos, por sua própria atividade pessoal”, embora ele "tenha sido arrastado, entre 1829 e 1834, exatamente para esse tipo de movimento" (THOMPSON, 1987a, v. 3, p. 382). As análises de Thompson sobre o papel exercido pela liderança de Owen são implacáveis:

Owen simplesmente tinha um vazio na mente, lá onde a maioria dos homens tem reações políticas. Parte da Nova $V$ isão era dedicada ao Príncipe Regente, parte a Wilberforce. Quinze anos depois, seu Crisis navegava suavemente entre as águas de 1831 e 1832, transportando carregamentos de relatórios sobre congressos cooperativos e armazéns comerciais em Slaithwaite, sem perceber que o país estava de fato num estado de crise revolucionária. (THOMPSON, 1987 a, v. 3, p. 384, grifo do autor).

Por mais admirável que Owen fosse como pessoa, era um pensador absurdo e, ainda que tivesse a coragem dos excêntricos, era um líder político nocivo. (THOMPSON, 1987 a, v. 3, p. 388). 
A improvável mistura entre paternalismo e utilitarismo que marcou o início da atuação de Owen, entretanto, acabou sendo tragada na onda utópica desencadeada pelos seus experimentos comunitários e pelo seu fomento à teoria socialista. Desse modo, apesar de todas as suas limitações como líder político, ele se converteu, segundo Thompson, na expressão de um "milenarismo secular". Owen acreditava que o caráter social era o produto involuntário de "uma multiplicidade infindável de circunstâncias", que poderia ser transformada, em longo prazo, pela educação, mas ele

sabia que, até que até que as "circunstâncias" se transformassem, não teria acesso à formação de uma geração. A resposta, portanto, devia se encontrar na mudança súbita do coração, no salto milenarista. O próprio rigor do seu materialismo ambiental e mecânico significava que teria ou de desesperar ou de proclamar um quiliasma secular. Sr. Owen, o Filantropo, jogou o manto de Joanna Southcott ao ombro. [...] Owen, em 1820, prometia "deixar correr a prosperidade pelo pais", e em suas comunidades oferecia nada menos que o "Paraíso". (THOMPSON, 1987a, v. 3, p. 388389).

Apesar das duras críticas a Owen como líder político mencionadas acima, é exatamente essa perspectiva utópica do "owenismo tardio" que Thompson valoriza. Ela teria contribuído decisivamente para superar o aspecto "estreito e negativo" da "propaganda racionalista da década anterior", que "gerara uma sede por uma doutrina moral mais positiva, atendida pelo messianismo de Owen" (THOMPSON, 1987a, v. 3, p. 399). Desse modo, "o anelo comunitário reviveu, e a linguagem da racionalidade foi transposta para a da fraternidade" (THOMPSON, 1987a, v. 3, p. 406). Paradoxalmente, teria sido a própria "imprecisão do pensamento de Owen" que, ao tornar "possível a coexistência de diferentes tendências dentro do movimento" contribuiu para gerar um movimento "mais saudável, e mais forte em termos intelectuais, do que o pensamento do seu mestre" (THOMPSON, 1987a, v. 3, p. 399). A grande 
diferença entre "o owenismo e credos anteriores que concentravam o impulso milenarista" é que no primeiro "o Milênio não estava por vir, estava por ser feito por seus próprios esforços" (THOMPSON, 1987a, v. 3, p. 407, grifo do autor). Além disso, "os líderes operários radicais" tinham aprendido com Owen "a ver o capitalismo como um sistema" e "a projetar um sistema de mutualismo alternativo e utópico", abandonando a nostalgia "por um mundo mais antigo e adquirido a confiança de planejar o novo", mas em 1832, "vinham rejeitando a posição de Owen de descartar todos os meios políticos" (THOMPSON, 1987a, v. 3, p. 410, grifo do autor).

\section{Conclusão}

Conforme demonstramos acima, os argumentos sobre a incompatibilidade entre a perspectiva thompsoniana fundada na agência histórica dos trabalhadores e o uso do conceito de populismo são infundados. É certo que o sentido em que o autor utiliza o conceito em três ocasiões distintas no seu principal trabalho não está marcado pela estigmatização das experiências analisadas, como ocorria com boa parte daquilo que foi tradicionalmente denominado de "teoria do populismo" na América Latina. Para Thompson, "populismo" designa a ênfase no protagonismo popular, uma perspectiva democrática radical (mas não ainda socialista) que distinguiu o movimento pela reforma política na Inglaterra em função da composição de sua base social e de sua trajetória histórica, ambas peculiares no período. Essa abordagem levanta a possibilidade de dissociarmos o conceito de "populismo" da ideia de "manipulação" ou "desvio de uma consciência política ideal".

O segundo item deste artigo, entretanto, chama a atenção para o fato de que Thompson não descarta a ideia de que a "manipulação de massas" possa ocorrer em determinadas circunstâncias. Também não se furta à análise crítica da dependência dos movimentos populares em relação a líderes oriundos das classes dominantes, que tendem a reproduzir concepções tradicionais de 
participação política, baseadas na dependência dos "pobres e humildes" em relação a "paladinos da justiça social", supostamente mais habilitados a defendê-los contra seus inimigos e opressores no terreno hostil da política. Por mais que a experiência coletiva possa ressignificar a participação política ocorrida sob a égide de tais lideranças e torná-la parte integrante do processo de formação de classe, não devemos nos esquecer de que ela expressa as debilidades circunstanciais dos movimentos de trabalhadores, e não a sua força. Para Thompson, porém, isso sequer chega a ser populismo, apenas demagogia.

Essas ideias do autor britânico podem, evidentemente, ser criticadas por reintroduzirem um elemento teleológico na análise da formação da classe trabalhadora. Ao invés de uma consciência ideal derivada de interesses históricos deduzidos de relações econômicas, o padrão da "maturidade" da classe seria dado por uma determinada configuração cultural e organizacional. Nas décadas de 1980 e 1990, novos expoentes da historiografia britânica vinculados ao chamado linguistic turn, tais como Gareth Stedman Jones (1983) e Patrick Joyce (1991), criticaram Thompson precisamente por isso. Infelizmente, não temos aqui espaço para analisar os desdobramentos desse debate, mas vale a pena ressaltar que foi a partir dele que Joyce formulou a tese de que boa parte da consciência política demonstrada pelos movimentos de trabalhadores na Inglaterra até a Primeira Guerra Mundial era "populista" e não "classista", tese que, se aceita, derruba definitivamente qualquer relação entre populismo e "desvio periférico", uma vez que estamos falando do que era, naquele período, o centro dinâmico do capitalismo mundial (ver JOYCE, 1991, especialmente: "Introduction: beyond class", p. 1-23 e o capítulo 3, "Class, populism and socialism: Liberalism and after", p. 56-84.).

Voltando ao caso brasileiro, poderíamos nos perguntar se, apesar de todas as imperfeições e ambiguidades do conceito, "populismo" não permaneceria sendo uma descrição razoavelmente adequada para o processo de incorporação planejada das massas trabalhadoras na política quando visto "de cima". É essa a perspectiva que marca $O A B C$ dos operários, de John French (1995), um trabalho que, embora não reivindique afiliação thompsoniana, 
tem como foco central a autoconstrução do movimento operário do ABC paulista na primeira metade do século XX. Isso, entretanto, não impede o autor de trabalhar com o conceito de populismo.

Analisando a contribuição de Francisco Weffort e outros autores cujos principais trabalhos foram publicados nos anos 1970 para o estudo do período de 1945 a 1964, French (1995, p. 76) aponta que

ao descobrir na liderança errada da esquerda a resposta para o paradoxo do populismo, simplesmente reformulavam a questão em plano diverso: Porque os operários seguiam líderes cujas políticas não só deixavam de defender com eficiência seus interesses, como ainda perpetuavam a dominação sobre eles dos empregadores e do Estado?

A segunda parte do livro de French abre-se precisamente com a análise do cenário de definição das estratégias macropolíticas traçadas por Vargas a partir da crise do Estado Novo, quando o ditador, "vendo-se diante de inimigos espalhafatosos e de amigos duvidosos", decidiu-se "por um rumo inesperado que iria afetar tanto a campanha eleitoral de 1945 quanto a história do Brasil: apoiar-se no povo trabalhador do país" (FRENCH, 1995, p. 101). Buscando evitar que as eleições significassem "um retorno aos vícios da Primeira República”, Vargas assumiu a necessidade de ampliação da esfera política, "de modo a incluir as pessoas do novo Brasil urbano-industrial, que estavam ausentes do PSD e da UDN" e, "sem rodeios, lançou os operários urbanos do país no centro do processo sucessório" (FRENCH, 1995, p. 101).

Até esse ponto, poderíamos considerar que não se trata de uma abordagem particularmente inovadora. Mas o que chama a atenção na obra de French é o modo como a metodologia adotada na articulação geral da análise torna compatível o uso do conceito de "populismo" e o reconhecimento da "agência histórica" dos trabalhadores. Apenas a título de exemplo, a segunda parte do livro, iniciada, como vimos acima, com o que ele denomina "a aposta populista de Getúlio Vargas" (FRENCH, 1995, p. 95-121) - ou seja, a história "vista de cima" - conclui-se com três capítulos nos 
quais o foco muda para a análise dos processos de organização e mobilização dos trabalhadores e para a sua reapropriação ativa do projeto político que visava à sua incorporação controlada à cidadania. $^{2}$

Considerando os exemplos e as ponderações acima, podemos concluir que os problemas tradicionalmente abordados à luz do conceito de populismo não são resolvidos pela simples supressão da sua utilização. Exemplificamos com algumas indagações:

1) Considerar os trabalhadores como sujeitos ativos, que desempenham um papel fundamental na sua própria constituição como classe, exclui a possibilidade de diferenciar entre processos de organização e participação política baseados em maior ou menor grau de autonomia de classe?

2) O fato da participação em lutas e organizações políticas se dar com base em conceitos e discursos "classistas" (nos quais a diferenciação de interesses entre classes desempenha papel central) ou "populistas" (nos quais as ideias de "povo" e, geralmente, de "nação" desempenham papel central) não é relevante para a análise histórica?

3) A relação de maior ou menor "organicidade" entre lideranças políticas apoiadas pela classe trabalhadora e suas bases (no que diz respeito a origem de classe, vinculação a organizações classistas) não deve ser examinada pelos historiadores?

Esperamos ter demonstrado que um estudo atento das análises de Thompson sobre o processo de formação de classe pode continuar a suscitar reflexões relevantes para o avanço na pesquisa histórica sobre as especificidades da classe trabalhadora no Brasil. Em particular, buscamos chamar a atenção para o fato de que elas têm muito a contribuir para o reexame de questões tradicionalmente associados ao debate sobre o "populismo". Não se trata, evidentemente, de buscar em Thompson a "solução" dessa ou de qualquer outra temática relevante da história do trabalho no Brasil. Muito menos de utilizá-lo como uma pretensa panaceia teórica ou como base para forjar argumentos de autoridade que interditem, ao invés de ampliar, o campo de debate historiográfico. 
Class formation and political participation: E. P. Thompson and populism

Abstract: The article focus the use of the concept of populism and the analysis of related phenomena in the works of the British historian E. P. Thompson, in particular The making of the English working class. The relevance of this exercise, from the viewpoint of Brazilian Labor History relies on the recently acquired relevance of Thompson's works as theoretical references for the studies on working-class political participation in the post-1930 period, traditionally approached under the light of that concept.

Keywords: Populism. British social history. E. P. Thompson. Working class. Political participation.

\section{Notas}

${ }^{1}$ A esse respeito, ver a minha crítica das análises de Ferreira (2000) sobre o depoimento do sindicalista do setor transviário (bondes) José Vecchio, primeiro presidente do PTB (Partido Trabalhista Brasileiro) do Rio Grande do Sul (FORTES, 2007).

2 "O getulismo popular e a organização da classe operária" (FRENCH, 1995, p. 122140), "Ler uma greve. Ação direta no início de 1946" (FRENCH, 1995, p. 151-176) e "Atingimos a maioridade. O operariado e o Estado" (FRENCH, 1995, p. 177190).

\section{Referências}

CHALHOUB, S.; SILVA, F. T. da. Sujeitos no imaginário acadêmico: escravos e trabalhadores na historiografia brasileira desde os anos 1980. Cadernos AEL, n. 26, p. 14-45, 2009.

FERREIRA, J. Sindicalismo, política e trabalhismo no Rio Grande do Sul: a trajetória de José Vecchio. In: REIS FILHO, D. A. (Org.). Intelectuais, história e política (séculos XIX e XX). Rio de Janeiro: 7 Letras, 2000. p. 182-218.

. O nome e a coisa: o populismo na política brasileira. In: FEREIRA, J. (Org.). O populismo e sua história: debate e crítica. Rio de Janeiro: Civilização Brasileira, 2001. p. 59-124.

FORTES, A. "Miríades por toda a eternidade": a atualidade de E. P. Thompson. Tempo Social, v. 18, n. 1, p. 197-215, 2006. 


\section{Alexandre Fortes}

FORTES, A.; SILVA, A. M. da. Revisitando um clássico da história social: a estrutura narrativa de A formação da classe operária inglesa. Revista Universidade Rural: Série Ciências Humanas, v. 29, p. 1-24, 2007.

FRENCH, J. D. O ABC dos operários: conflitos e alianças de classe em São Paulo, 1900-1950. São Paulo: Hucitec; Prefeitura Municipal de São Caetano do Sul, 1995. GOMES, A. de C. A invenção do trabalbismo. São Paulo: Vértice; Iuperj, 1988.

. O populismo e as ciências sociais no Brasil. Notas sobre a trajetória de um conceito. In: FEREIRA, J. (Org.). O populismo e sua bistória: debate e crítica. Rio de Janeiro: Civilização Brasileira, 2001. p. 17-58.

JONES, G. S. Languages of class: studies in English working-class history, 18321982. Cambridge: Cambridge University Press, 1983.

JOYCE, P. Visions of the people: industrial England and the question of class, 18481914. Cambridge: Cambridge University Press, 1991.

NEGRO, A. L. Paternalismo, populismo e história social. Cadernos AEL. n. 20/21, p. 11-37, 2004.

RUDÉ, G. Wilkes and liberty. Oxford: Oxford University Press, 1962.

SILVA, F. T. da; COSTA, H. da. Trabalhadores urbanos e populismo: um balanço dos estudos recentes. In: FEREIRA, J. (Org.). O populismo e sua história: debate e crítica. Rio de Janeiro: Civilização Brasileira, 2001. p. 205-271.

THOMPSON, E. P. A miséria da teoria ou um planetário de erros: uma crítica ao pensamento de Althusser. Rio de Janeiro: Zahar, 1981. - A formação da classe operária inglesa. Rio de Janeiro: Paz e Terra, 1987a. 3 v. . Senhores e cacadores. Rio de Janeiro: Paz e Terra, 1987b. . Tradición, revuelta y consciencia de clase. 3. ed. Barcelona: Crítica, 1989. . Costumes em comum. São Paulo: Companhia das Letras, 2002.

Recebido em: 17/03/2010 Aprovado em: 30/04/2010 